\title{
Continued deceleration of Whillans Ice Stream, West Antarctica
}

\author{
I. Joughin, ${ }^{1}$ R. A. Bindschadler, ${ }^{2}$ M. A. King, ${ }^{3}$ D. Voigt, ${ }^{4}$ R. B. Alley, ${ }^{4}$ \\ S. Anandakrishnan, ${ }^{4}$ H. Horgan, ${ }^{4}$ L. Peters, ${ }^{4}$ P. Winberry, ${ }^{4}$ S. B. Das, ${ }^{5}$ and G. Catania ${ }^{6}$ \\ Received 5 August 2005; revised 26 September 2005; accepted 11 October 2005; published 17 November 2005.
}

[1] Earlier observations indicated that Whillans Ice Stream slowed from 1973 to 1997 . We collected new GPS observations of the ice stream's speed in 2003 and 2004. These data show that the ice stream is continuing to decelerate at rates of about $0.6 \% / \mathrm{yr}^{2}$, with faster rates near the grounding line. Our data also indicate that the deceleration extends over the full width of the ice plain. Extrapolation of the deceleration trend suggests the ice stream could stagnate sometime between the middle of the 21st and 22nd Centuries. Citation: Joughin, I., et al. (2005), Continued deceleration of Whillans Ice Stream, West Antarctica, Geophys. Res. Lett., 32, L22501, doi:10.1029/ 2005 GL024319.

\section{Introduction}

[2] It is often assumed that ice sheets evolve with millennial-scale dynamic response times [Paterson, 1994]. Recent measurements, however, show far more rapid changes in speed on several large outlet glaciers and ice streams [e.g., Joughin et al., 2004a; Rignot et al., 2002, 2004; Scambos et al., 2004]. While many of these glaciers are accelerating, Whillans Ice Stream, one of several large ice streams feeding the Ross Ice Shelf in West Antarctica, slowed by 23\% from 1973 to 1997 [Joughin et al., 2002]. Although this part of the ice sheet has retreated significantly over the Holocene [Conway et al., 1999], the Ross Ice Streams are now collectively thickening [Joughin and Tulaczyk, 2002], largely because of Kamb Ice Stream's stagnation $\sim 140$ years ago [Retzlaff and Bentley, 1993].

[3] In addition to its observed slowdown, estimates of the thermal balance indicate widespread freezing beneath much of Whillans Ice Stream [Joughin et al., 2004b; Raymond, 2000], which may dewater and strengthen the till [Tulaczyk et al., 2000] if insufficient water is produced beneath the ice stream's tributaries or if the basal water system does not distribute that water sufficiently [Bougamont et al., 2003; Parizek et al., 2003].

\footnotetext{
${ }^{1}$ Polar Science Center, Applied Physics Lab, University of Washington, Seattle, Washington, USA.

${ }^{2}$ NASA Goddard Space Flight Center, Greenbelt, Maryland, USA.

${ }^{3}$ School of Civil Engineering and Geosciences, University of Newcastle, Newcastle upon Tyne, UK.

${ }^{4}$ Department of Geosciences and Earth and Environmental Systems Institute, Pennsylvania State University, University Park, Pennsylvania, USA.

${ }^{5}$ Department of Geology and Geophysics, Woods Hole Oceanographic Institution, Woods Hole, Massachusetts, USA.

${ }^{6}$ Institute for Geophysics, University of Texas at Austin, Austin, Texas, USA.
}

Copyright 2005 by the American Geophysical Union. 0094-8276/05/2005GL024319\$05.00
[4] Recent GPS observations indicate that Whillans Ice Stream moves in short $(<1 \mathrm{hr})$ high-speed $(\sim 10 \mathrm{~km} / \mathrm{yr})$ lurches, each followed by several hours of virtually no motion [Bindschadler et al., 2003a]. While stuck, elastic strain builds between the "stuck" area and the still rapidly flowing upstream region [Bindschadler et al., 2003b]. The ice shelf's tidally driven displacement just seaward of the grounding line also contributes to the ice stream's force balance. When the combined driving stress from the local surface slope, the push from upstream, and the tidal influence exceed the till or the ice-till interface's failure threshold, the ice stream slips forward by roughly half a meter.

[5] When the ice stream sticks, it effectively stagnates for much of the day. This occurs during times of rising stress imbalance as the push from upstream increases and the tide falls, demonstrating considerable bed strength. If the bed strengthens over the long term, the upstream push will need to increase to maintain motion. Eventually, with sufficient bed strengthening, the required stresses will be large enough to yield a transition from elastic to viscous behavior, eliminating the upstream push and allowing the downstream portion to stagnate. This may have happened to Kamb Ice Stream, where ice above the stagnant region is deforming to produce a bulge rather than building elastic strain [Joughin et al., 1999]. The multi-decadal deceleration, basal freezing conditions, and stick-slip behaviour all suggest that Whillans Ice Stream may be on a path to stagnation [Bougamont et al., 2003] similar to neighbouring Kamb and Siple Ice Streams [Gades et al., 2000].

\section{Results}

[6] To further investigate stick-slip behaviour and the long-term deceleration, we placed GPS receivers on the ice stream in 2003 and 2004 (Figure 1). Here we compare these data with earlier observations to determine if the deceleration is continuing. The 2003 stations recorded data continuously for $\sim 70$ days. A larger set of stations acquired data for up to 44-day periods in late 2004. Point solutions were generated every 5 min using the Precise Point Positioning technique in the GIPSY software [King and Aoki, 2003]. The position precision is $25 \mathrm{~mm}$ in each coordinate, based on the weighted root-mean-square of the coordinates of a uniformly moving site. Our analysis ignores these errors because they are negligible relative to the observed 25-to$125 \mathrm{~m}$ displacements.

[7] Stick-slip motion affects the accuracy of velocities determined from displacements measured over periods of several weeks in two ways. First, since slip occurs in discrete events, velocity estimates can differ significantly (e.g., a few $\mathrm{m} / \mathrm{yr}$ ) if the observation period terminates just before or after a slip event. To mitigate such errors, we 


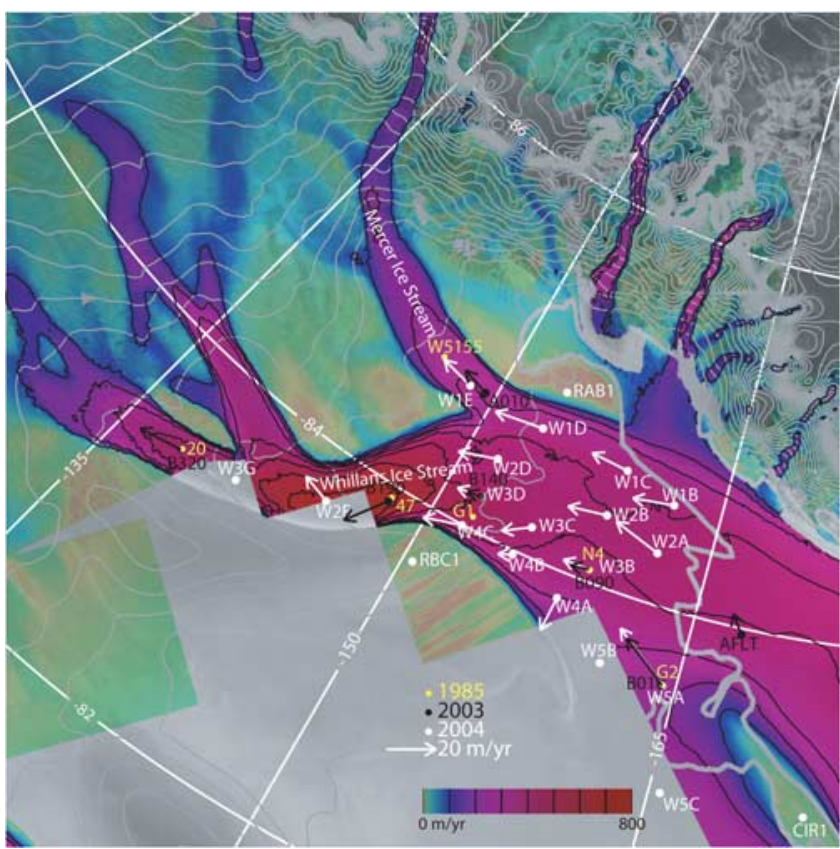

Figure 1. Changes in velocity from 1997 to 2003 (black vectors) and 1997 to 2004 (white vectors). The 1997 InSAR speeds are shown both with color and $100-\mathrm{m} / \mathrm{yr}$ contours (black lines) over the RAMP SAR mosaic. Small circles and text indicate 1985, 2003, and 2004 station locations.

estimated velocities using time intervals equal to integermultiples of days. Second, the tide can affect the speed over its 28-day spring-neap cycle. To evaluate this effect, we broke our longer records into several overlapping subintervals from which we determined velocity. Figure 2 shows the maximum difference in these multiple estimates relative to the mean speed as a function of sub-interval length for five stations. Errors are reduced below $5 \mathrm{~m} / \mathrm{yr}$ for observation intervals of $\sim 35$ days or longer. Errors are larger where stick-slip motion is strong (B010) and are smaller where stick-slip motion is weak (B190) or nearly non-existent (B320). The overlapping sub-intervals yield correlated estimates, and we did not have enough samples to get a good estimate of the standard error. Because they represent the maximum difference over more than half a tidal spring-neap cycle, we treat these errors as roughly approximating 3-sigma errors.

[8] In 1997 RADARSAT collected Synthetic Aperture Radar (SAR) data for regions south of $80^{\circ} \mathrm{S}$. Interferometric SAR (InSAR) techniques were used to produce a velocity map (Figure 1) of Whillans Ice Stream [Joughin et al., 2002, 1999]. Because the InSAR pairs are separated by only 24 days, the velocity estimates contain stick-slip induced errors (e.g., Figure 2). There are also instrumental InSAR errors of up to several meters per year. As described above, we approximate the stick-slip errors (e.g., Figure 2) as 3-sigma errors to combine them with the 3-sigma InSAR errors.

[9] Several of our GPS stations are situated at or near locations where velocity was measured using Transit satellite receivers during the Siple Coast Project (SCP) in the mid 1980s (20, 47, W5155, G1, G2, and N4 in Figure 2) [Whillans and van der Veen, 1993]. The quality of these data varies, so we applied the largest published estimate of $25 \mathrm{~m} / \mathrm{yr}$ for the 3-sigma errors to all the SCP data [Stephenson and Bindschadler, 1988].

[10] We positioned five GPS stations on Whillans Ice Stream (Bnnn) and one on Mercer Ice Stream (A010) in 2003. Figure 3 shows the station speeds along with those from the 1997 InSAR, SCP stations, and 2004 stations. For comparisons with the SCP data, we chose the closest SCP station to each of our 2003 stations.

[11] Near the grounding line, B010 (SCP station G2), shows steady deceleration of $3.9 \mathrm{~m} / \mathrm{yr}^{2}$ over the period from 1985 to 2004. As a percentage of the mean velocity, this station showed the strongest deceleration. In 1999 a new pole was surveyed at approximately the same coordinates as the original G2 station. In 2003 we serendipitously found the 1999 pole $\sim 400 \mathrm{~m}$ away from B010. We resurveyed this pole in 2004 and used the results to compute a 5-year mean velocity (Figure 3a). While the 19-year deceleration at B010 appears relatively steady, two points measured in the mid 1970s within about $60 \mathrm{~km}$ of this site [Thomas et al., 1984] suggest that the pre-1985 rate of deceleration may have been larger [Joughin et al., 2002; Stephenson and Bindschadler, 1988].

[12] Station B090 (Figure 3b) decelerated at a rate of $1.1 \mathrm{~m} / \mathrm{yr}^{2}$ from 1997 to 2003 , which is small relative to the 19 -year average of $3.9 \mathrm{~m} / \mathrm{yr}^{2}$. From 2003 to 2004, however, the station decelerated at $4.3 \mathrm{~m} / \mathrm{yr}^{2}$. Similar rates were observed at B140, which is located at the ice plain's upstream end. The closest SCP station is G1, which is located approximately $13 \mathrm{~km}$ away. The similar InSAR values at G1 and B140 (Figure 3c) indicate that spatial velocity gradients are fairly small in this area, so that it is reasonable to compare results from these two stations. Together the $\mathrm{B} 090$ and $\mathrm{B} 140$ results suggest that the stick-slip motion may have biased the 1997 estimates low. Alternatively, stick-slip motion may cause deceleration to be more temporally variable on this part of the ice plain.

[13] On the ice stream's fastest-moving section, station B190 (Figure 3b) underwent the largest deceleration $\left(4.6 \mathrm{~m} / \mathrm{yr}^{2}\right)$. As a percentage of its mean speed, however, this deceleration $(0.62 \% / \mathrm{yr})$ is comparable to the rates at neighbouring stations B140 and B320. This station's deceleration from 1997 to 1992 was smaller $\left(3.1 \mathrm{~m} / \mathrm{yr}^{2}\right)$ than the 19 -year average, but deviates from the linear trend by less than the margin of error. Farther upstream at station B320 (Figure 3e), the ice stream slowed steadily at $2.6 \mathrm{~m} / \mathrm{yr}^{2}$.

[14] On Mercer Ice Stream, the stations are located too far apart to directly compare results. We can, however, compare

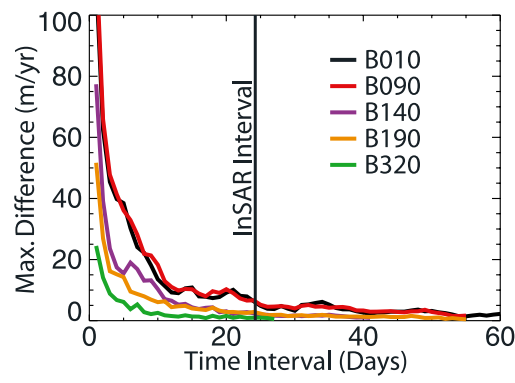

Figure 2. Maximum difference between individual velocity estimates and mean velocity as a function of time interval used to compute velocity. 

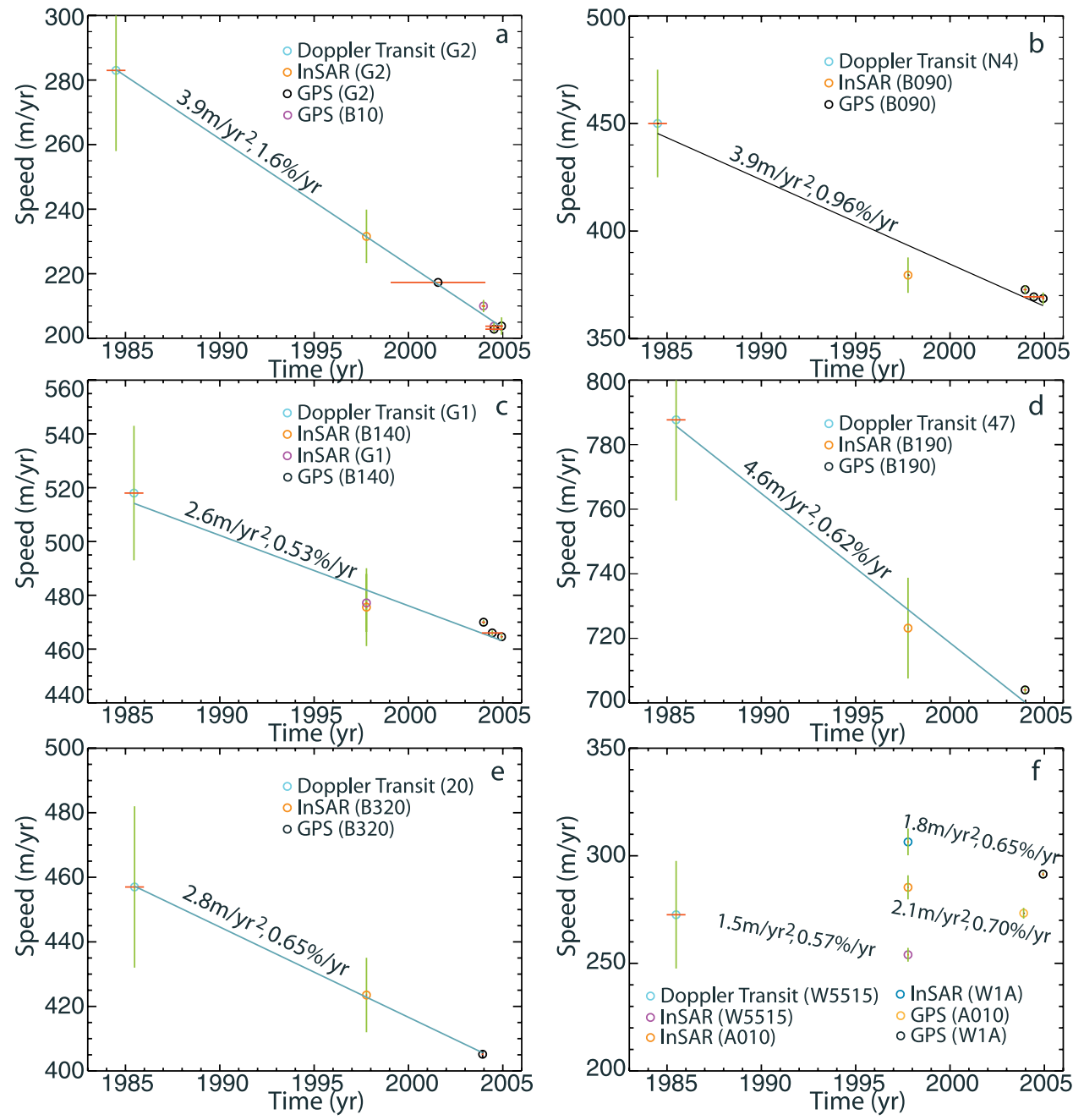

Figure 3. Plots of velocity versus time at station locations shown in Figure 1. Green vertical lines show $\sim 3$ sigma error bars (see text) and red horizontal lines show intervals over which displacements were observed to calculate velocity. Note each plot has a different scale along the y-axis.

each station to the 1997 InSAR data (Figure 3f). The results all show comparable decelerations (1.5 to $\left.2.1 \mathrm{~m} / \mathrm{yr}^{2}\right)$ relative to the 1997 data. These stations along with stations B190 and B320 indicate that the regions upstream of the ice plain are slowing at a relatively constant rate of about $0.6 \% / \mathrm{yr}$.

[15] All of our 2003 (Bnnn) stations are at points that ultimately drain to the north of Crary Ice Rise. This is important since flow-stripes preserved in the ice shelf suggest differing flow histories across the ice rise [Fahnestock et al., 2000]. In 2004, we deployed 28 stations covering the ice plain's full width. The changes at these stations (Figure 1) relative to 1997 reveal a consistent pattern of deceleration across the entire ice plain. The only point that differs significantly from this pattern is station W4A, which is located near a strong velocity gradient. The InSAR velocities are smoothed to $\sim 2.5 \mathrm{~km}$ resolution, so this gradient is a likely source of the anomaly.

\section{Discussion}

[16] Our observations reveal that deceleration continued at least through 2004. At the ice stream's upper and lower reaches, the deceleration continued at rates similar to earlier observations. In the ice plain's middle, the data indicate less deceleration from 1997 to 2003, which may reflect an actual change or errors in the 1997 data. The 2003-to-2004 rates, however, agree well with the long-term average. These measurements and earlier observations [Joughin et al., 2002; Stephenson and Bindschadler, 1988; Thomas et al., 1984] indicate deceleration at a more or less steady rate over the past 30 years (1974 to 2004), suggesting the ice stream may be on a path to stagnation [Bougamont et al., 2003]. The larger deceleration rates (as percentages) near the grounding line suggest that the deceleration originates on the ice plain, farthest removed from upglacier sources of meltwater and where basal freezing rates are the greatest [Joughin et al., 2004b; Raymond, 2000].

[17] Although we cannot rule out the possibility that ice stream speeds may eventually stabilize, extrapolation of the 19-year trend suggests that flow at B010 could cease completely by $\sim 2057$ and at B320 by $\sim 2149$. Through reduced basal shear heating, continued deceleration will increase basal freezing beneath the ice plain and reduce basal melting farther upstream, potentially strengthening the till and hastening stagnation. Hence, it is possible that the ice stream could stagnate even more abruptly than the 
current trend suggests which would slow the rate of sealevel rise by $\sim 0.08 \mathrm{~mm} / \mathrm{yr}$.

[18] Acknowledgments. This work was supported by the National Science Foundation (NSF-OPP-0229659). IJ's contribution was supported by the Cryospheric Sciences Program of NASA's Earth Science Enterprise. We thank S. Marshall, S. Tulaczyk, and the anonymous reviewer for their careful reviews of the manuscript.

\section{References}

Bindschadler, R. A., P. L. Vornberger, M. A. King, and L. Padman (2003a), Tidally driven stick-slip motion in the mouth of Whillans Ice Stream, Antarctica, Ann. Glaciol., 36, 263-272.

Bindschadler, R. A., M. A. King, R. B. Alley, S. Anandakrishnan, and L. Padman (2003b), Tidally controlled stick-slip discharge of a West Antarctic ice stream, Science, 301, 1087-1089.

Bougamont, M., S. Tulaczyk, and I. Joughin (2003), Numerical investigations of the slow-down of Whillans Ice Stream, West Antarctica: Is it shutting down like Ice Stream C?, Ann. Glaciol., 37, 239-246.

Conway, H., B. L. Hall, G. H. Denton, A. M. Gades, and E. D. Waddington (1999), Past and future grounding-line retreat of the West Antarctic Ice Sheet, Science, 286, 280-283.

Fahnestock, M. A., T. A. Scambos, R. A. Bindschadler, and G. Kvaran (2000), A millennium of variable ice flow recorded by the Ross Ice Shelf, Antarctica, J. Glaciol., 46, 652-664.

Gades, A. M., C. F. Raymond, H. Conway, and R. W. Jacobel (2000), Bed properties of Siple Dome and adjacent ice streams, West Antarctica, inferred from radio-echo sounding measurements, J. Glaciol., 46, 88-94.

Joughin, I., and S. Tulaczyk (2002), Positive mass balance of the Ross Ice Streams, West Antarctica, Science, 295, 476-480.

Joughin, I., L. Gray, R. Bindschadler, S. Price, D. Morse, C. Hulbe, K. Mattar, and C. Werner (1999), Tributaries of West Antarctic Ice streams revealed by RADARSAT interferometry, Science, 286, $283-$ 286

Joughin, I., S. Tulaczyk, R. Bindschadler, and S. F. Price (2002), Changes in West Antarctic ice stream velocities: Observation and analysis, J. Geophys. Res., 107(B11), 2289, doi:10.1029/2001JB001029.

Joughin, I., W. Abdalati, and M. Fahnestock (2004a), Large fluctuations in speed on Greenland's Jakobshavn Isbrae glacier, Nature, 432, 608610

Joughin, I., S. Tulaczyk, D. R. MacAyeal, and H. Engelhardt (2004b), Melting and freezing beneath the Ross ice streams, Antarctica, J. Glaciol., 50, 96-108.

King, M., and S. Aoki (2003), Tidal observations on floating ice using a single GPS receiver, Geophys. Res. Lett., 30(3), 1138, doi:10.1029/ 2002 GL016182.
Parizek, B. R., R. B. Alley, and C. L. Hulbe (2003), Subglacial thermal balance permits ongoing grounding-line retreat along the Siple Coast of West Antarctica, Ann. Glaciol., 36, 251-256.

Paterson, W. S. B. (1994), The Physics of Glaciers, 3rd ed., 480 pp., Elsevier, New York.

Raymond, C. F. (2000), Energy balance of ice streams, J. Glaciol., 46, $665-674$.

Retzlaff, R., and C. R. Bentley (1993), Timing of stagnation of Ice Stream-C, West Antarctica, from short-pulse radar studies of buried surface crevasses, J. Glaciol., 39, 553-561.

Rignot, E., D. G. Vaughan, M. Schmeltz, T. Dupont, and D. MacAyeal (2002), Acceleration of Pine Island and Thwaites Glaciers, West Antarctica, Ann. Glaciol., 34, 189-194.

Rignot, E., G. Casassa, P. Gogineni, W. Krabill, A. Rivera, and R. Thomas (2004), Accelerated ice discharge from the Antarctic Peninsula following the collapse of Larsen B ice shelf, Geophys. Res. Lett., 31, L18401, doi:10.1029/2004GL020697.

Scambos, T. A., J. A. Bohlander, C. A. Shuman, and P. Skvarca (2004), Glacier acceleration and thinning after ice shelf collapse in the Larsen B embayment, Antarctica, Geophys. Res. Lett., 31, L18402, doi:10.1029/ 2004GL020670.

Stephenson, S. N., and R. A. Bindschadler (1988), Observed velocity fluctuations on a major Antarctic ice stream, Nature, 334, 695-697.

Thomas, R. H., D. MacAyeal, D. H. Eilers, and D. R. Gaylord (1984), Glaciological studies on the Ross Ice Shelf, Antarctica, 1973-1978, in The Ross Ice Shelf: Glaciology and Geophysics, Antarct. Res. Ser., edited by C. R. Bentley and D. E. Haynes, pp. 21-53, AGU, Washington, D. C.

Tulaczyk, S., W. B. Kamb, and H. F. Engelhardt (2000), Basal mechanics of Ice Stream B, West Antarctica: 1. Till mechanics, J. Geophys. Res., 105, $463-481$.

Whillans, I. M., and C. J. van der Veen (1993), New and Improved Determinations of Velocity of Ice Stream-B and Ice Stream-C, West Antartica, J. Glaciol., 39, 483-490.

R. B. Alley, S. Anandakrishnan, H. Horgan, L. Peters, D. Voigt, and P. Winberry, Department of Geosciences, Pennsylvania State University, University Park, PA 16802, USA.

R. A. Bindschadler, NASA Goddard Space Flight Center, Greenbelt, MD 20771, USA.

G. Catania, Institute for Geophysics, University of Texas at Austin, Austin, TX 78759, USA.

S. B. Das, Department of Geology and Geophysics, Woods Hole Oceanographic Institution, Woods Hole, MA 02543, USA.

I. Joughin, Polar Science Center, Applied Physics Lab, University of Washington, 1013 NE 40th Street, Seattle, WA 98105, USA. (ian@apl. washington.edu)

M. A. King, School of Civil Engineering and Geosciences, University of Newcastle, Newcastle upon Tyne NE1 7RU, UK 